\title{
Empowerment of Women: A Conceptual Framework
}

\author{
Dr. Anu Dandona ${ }^{1}$
}

\section{ABSTRACT:}

The term empowerment has been widely used in the social sciences across a broad variety of disciplines. Empowerment in woman's development is a way of defining, challenging and overcoming barriers in her life through which she increases her ability to shape her life. The process of empowerment will not only be able to improve their skills and access to productive resources, but also succeed in enhancing quality, dignity and work in the society status. The effect of empowerment of women creates a powerful influence on the norms, values and finally the laws that govern these communities (Cheryl 1999; Czuba 1999; Nanette 1999; Page 1999). Empowerment includes cognitive and psychological elements, such as a women's understanding of her condition of subordination and the causes of such conditions. This requires an understanding the self and the cultural and social expectations, which may be activated by education.

Keywords: Empowerment, Women, Challenges, Cognitive and Psychological Elements.

"To call woman the weaker sex is a libel; it is man's injustice to woman. If by strength is meant brute strength, then, indeed, woman is less brute than man. If by strength is meant moral power, then woman is immeasurably man's superior: Has she not greater intuition, is she not more self-sacrificing, has she not greater powers of endurance, has she not greater courage? Without her man could not be. If non-violence is the law of our being, the future is with woman. Who can make a more effective appeal to the heart than woman?"

Mahatma Gandhi

Empowerment can be viewed as means of creating a social environment in which one can make decisions and make choices either individually or collectively for social transformation. It strengthens the innate ability by way of acquiring knowledge, power and experience (Hashemi Schuler and Riley, 1996).

Empowerment is the process of enabling or authorizing individual to think, take action and control work in an autonomous way. It is the process by which one can gain control over one's destiny and the circumstances of one's lives. Empowerment includes control over resources (physical, human, intellectual and financial) and over ideology (beliefs, values and attitudes) (Baltiwala, 1994).

\footnotetext{
${ }^{1}$ Assistant Professor, AIBAS, Amity University, Lucknow.
} 


\section{Empowerment of Women: A Conceptual Framework}

It is not merely a feel of greater extrinsic control, but also grows intrinsic capacity, greater selfconfidence and an internal transformation of one's consciousness that enables one to overcome external barriers to accessing resources or changing traditional ideology (Pinto, 2001).

Empowerment of women is essentially the process of upliftment of economic, social and political status of women, the traditionally underprivileged ones, in the society. It is the process of guarding them against all forms of violence. Women empowerment involves the building up of a society, a political environment, wherein women can breathe without the fear of oppression, exploitation, apprehension, discrimination and the general feeling of persecution which goes with being a woman in a traditionally male dominated structure. Deepa Narayan in her edited book 'Measuring Empowerment' (www.oup.com) takes "Empowerment as the expansion of assets and capabilities of poor people to participate in, negotiate with, influence control and hold accountable institutions that affect their lives "

Women's empowerment is very essential for the development of society. Empowerment means individuals acquiring the power to think and act freely, exercises choice and fulfil their potential as full and equal members of society. As per the United National Development Fund for women (UNIFEM), the term women's empowerment means:

- Acquiring knowledge and understanding of gender relations and the ways in which these relations may be changed.

- Developing a sense of self-worth, a belief in one's ability to secure desired changes and the right to control one's life.

- Gaining the ability to generate choices exercise bargaining power.

- Developing the ability to organize and influence the direction of social change, to create a more just social and economic order, nationally and internationally.

Thus, empowerment means a psychological sense of personal control or influence and a concern with actual social influence, political power and legal rights. It is a multilevel construct referring to individuals, organizations and community. It is an international, ongoing process centered in the local community, involving mutual respect, critical reflection, caring and group participation, through which people lacking an equal share of valued resources gain greater access to the control over these resources.

\section{LITERATURE REVIEW}

The literature on female empowerment largely follows two approaches. The first set of studies considers the determinants of female empowerment. The second set of studies examines different proxies for female empowerment. Female empowerment is measured by a woman's ability to make household decisions, relative to her husband's ability to make household decisions. Since this ability cannot be explicitly measured, economists study whether variables such as education, contraceptive use, and asset-ownership are correlated with high female empowerment. These self-reported variables reflect the wide variety of choices and decisions at stake in the household bargain: employment, fertility, and resource allocation. Empowerment itself has been measured by a woman's relative physical mobility, economic security, decision-making ability, freedom 


\section{Empowerment of Women: A Conceptual Framework}

from domestic violence, and political awareness and participation. A large body of literature finds that a woman's access to employment outside the house increases her household bargaining power (for a study in Bangladesh, see Anderson and Eswaran, 2009; for a study in India, see Rahman and Rao, 2004). The ownership of assets, in particular, is one important way through which access to employment helps empower women in developing countries (for example, see Agarwal, 2001, for evidence from India). In addition, several analyses have found that access to credit programs - whether through micro-finance organizations or rotating savings and credit associations (ROSCA) - has a positive effect on female empowerment (for a study in Kenya, see Anderson and Baland, 2002; for a study in Bangladesh, see Hashemi, Schuler and Riley, 1996). Studies have also found a positive link between empowerment and contraceptive use (for a study in Bangladesh, see Schuler and Hashemi, 1994), as well as between the woman's influence on resource allocation and her family's social status (for a study in Bangladesh, see Quisumbing and de la Briere, 2000). In particular, the more educated she and her father are relative to her husband, the more empowered she is. Relative physical mobility is another important determinant of autonomy, defined as degree of control over microcredit loans, since it reflects the woman's access to outside employment opportunities (Hashemi, Schuler and Riley, 1996). A study of the determinants of female autonomy in India finds that a better-educated woman has greater bargaining power, as measured by physical mobility and say in household resource allocation, through the channel of increased information (Rahman and Rao, 2004). The same study also finds culture, as measured by state fixed-effects, to significantly increase bargaining power despite controlling for religion and caste. Further evidence from India shows strong positive correlations between female education as a proxy for bargaining power, and freedom of movement and better maternal health as bargaining outcomes (see Malhotra, Pande and Grown, 2003 for a review of this literature). The literature further agrees that the clearing of marriage markets depends on the number of men and women in the market (for theoretical models, see Becker, 1973a,b; Neelakantan and Tertilt, 2008). As a result, the local sex ratio works through the spousal age ratio to influence marriage markets and therefore household bargaining power. Scholars have found that, particularly in the Indian context, women have less bargaining power if their husbands are significantly older (for evidence from India, see Caldwell, Reddy and Caldwell, 1983; Kantor, 2003). Since empowerment is an unobservable latent variable, economists use its observable characteristics as proxies for empowerment. Women with high values of the proxies, such as a greater spousal age ratio, access to outside employment or a high level of political participation, are also likely to have greater bargaining power. Thus, the indicators of a high level of empowerment include (1) access to outside employment, (2) physical mobility, and (3) political participation (Anderson and Eswaran, 2009; Hashemi, Schuler and Riley, 1996; Rahman and Rao, 2004). The corresponding dependent variables we use to reflect high levels of female autonomy are (1) the ownership of identification cards for the national government's rural employment guarantee scheme, which proxies for access to outside employment, (2) the ability to leave the household without permission, which reflects physical mobility, and (3) participation in weekly village council meetings, which measures political participation. We choose these variables because they represent a diverse set of ways in which 


\section{Empowerment of Women: A Conceptual Framework}

the Mahila Samakhya program can potentially empower women. With the exception of analyses of credit extension mechanisms, the studies discussed above focus on interventions targeted at the individual. Only a small number of papers look at community-level interventions. For instance, Imai and Eklund (2008) use survey data on a women's community-based organization in rural Papua New Guinea to assess the effectiveness of autonomous women's groups compared to those that receive external support. Their analysis - using a Heckman Selection Model as well as Propensity Score Matching - shows that the autonomous groups are more effective in improving child welfare. Thus, community-level interventions targeted at women can generate significant benefits to children's well-being. One of the few analyses of Mahila Samakhya uses data from the state of Bihar to evaluate the program's effect on community-level trust and social capital (Janssens, 2010). The paper uses Propensity Score Matching to calculate Intent-to-Treat estimates of the program. Matching women from treated villages to those from untreated villages, results suggest that the program significantly increases trust and engenders social capital. Participants are more likely to contribute to local educational and infrastructural community projects. Significant spillovers also exist with nonparticipants; non-participant households in program villages exhibit higher levels of trust and are more likely to engage in community building activities than households in non-program villages. Other work examines allied aspects of the program without explicitly evaluating it: Kandpal and Baylis (2013) ask whether participation affects the diversity of participants' peer group, while Kandpal and Baylis (2011) examine whether friends' participation improves female bargaining power and child welfare outcomes. None of these studies considers the causal model behind the mechanisms of community-level interventions. Next, we present a model that decomposes the effect of program participation in a community-level intervention.

\section{Education and work as determinants of women empowerment}

Many studies that have been dedicated to this subject consider the formal education and organizational work as the effective factors of women empowerment. When women have formal education and enter universities and then start doing part time or full time jobs in organizations, they can have a better control over their lives. Studies show that in developing countries, education and employment strengthen the situation of women in society, and increase their authority and power (Mason, et.al 2002). Also, according to the researches done in western countries, education and working empower women and increase their effectiveness in their personal, social and organizational life (Connel, 1987).

In the contemporary world, knowledge is one of the sources of power. The contemporary world has witnessed those powers of force and money (military and economic power) have been replaced by the power of knowledge. Gaining knowledge leads to power and lack of knowledge for women leads to their poverty. When women gain the required knowledge for having skill and power, the feeling of psychological enablement strengthens in them (Spreitzer, 1996). Lots of studies have considered illiteracy of women as the main cause of their problems and literacy as the cause of their freedom (Stromquist, 1997). Therefore, it is necessary for women of each society to gain the required knowledge for being involved in decision-making. 


\section{Empowerment of Women: A Conceptual Framework}

Women face main challenges in making a balance between their personal and working life; their challenges are much more compared to that of men (Nelson, Burke, 2000). Most researches show a clear division of responsibilities, namely men take responsibility for doing job outside the house and women take liability for children and housework such as cooking (Sharpi, 1984; Berk, 1985; Pleck, 1985; Warde and Hetherington, 1993; Baxter, 1993; Sullivan, 1996). Also, women spend two times more time for doing housework compared to men (Berk, 1985; Baxter, 1993; Sullivan, 1996). Many studies indicate that women, in spite of their great responsibility, are satisfied with the division of work in the house (Benin and Agostinelli, 1988; Blair and Johnson, 1992; Lennon and Rosenfield, 1994; Greenstein, 1996; DeMaris and Longmore, 1996). These results raised some questions about justice and equality at home and the approach towards housework and the possibilities of changing it. To explain these paradoxical clichés some theories have been offered, for example lack of sources and power in marriage make women to have little choices in regard to these clichés; the traditional ideology of gender makes women accept house work, and finally, the fact that women work less than their husbands outside the house, strengthens the approach that house work is the responsibility of women (Baxter and Western, 1998).

Power relation in family is one of the subjects under study in the familial institution. When the power gap in family is large, women and children are taught to obey and they are not encouraged to be independent. Women in these kinds of societies learn to accept the unequal division of power (Hofstede, 2001, ch. 2). In modern time, in western societies, the power gap between men and women has decreased. Women's education and income have given them more power in the family. But, the experiences of non-western societies may not be similar to those of western ones. Providing education and occupation for women is the required but not the sufficient condition for empowerment of women. A study undergone in China shows that having more access to education and job opportunities does not necessarily lead to change of power relations in the family (Wolf, 1992). In patriarchal societies, having access to education and having income do not necessarily bring independence and the culture is in a way that does not let women make decisions independently. For example, a research that was done in two areas in north India shows that although women had formal education and occupation, patriarchy was an obstacle on the way of their empowerment (Sharma, 1991, p. 92).

\section{Women Psychological Empowerment}

Empowerment means to grant or delegate power to someone (Conger and Kanungo 1988: 474). Empowerment refers to "the process of influencing over events and important conclusions for an individual or a team" (Fawcett et al., 1994:471). The term power means the capacity to obtain a desirable result (Russell, 1962). Empowerment is a process whereby an individual believes in his or her efficacy. Empowerment tends to be more talked about at the cognitive level than realized in practice. It is not a personal characteristic but it is a dynamic process that reflects an individual's opinions about person-environment relationship (Mishra and Spreitzer, 1998:579; Siegall and Gardner, 1999:705). Thus the true benefits of empowerment will not be discovered 


\section{Empowerment of Women: A Conceptual Framework}

unless people first perceive themselves as being powerful (Siegall and Gardner, 1999: 705). Empowerment of women means acquiring the power to think, acting freely, developing a sense of self-worth, a belief in one's ability to make desired changes and the right to control one's life, exercise choice, bargaining power, and fulfilling their potentiality as equal members of society. Generally empowerment is any process and activity by which women control their lives. Empowerment-related literature can generally be grouped into four categories. Individualoriented that includes personal feelings, personal power, self-determination, and other cognitive variables (Baird, 1994; Fulford and Enz, 1995; Spreitzer, 1995), result-oriented studies that have examined successful cases of empowerment (Berman, 1995; Burbidge, 1995). Operationoriented literature that explains the quality of meeting empowerment through organizational delayering, employee involving, establishing commitment, teaming, and intervening (Bogg, 1995; Lashley, 1995; Nixon, 1994; Osborne, 1994). Trait-oriented research is characterized by exploring the preconditions of control and power, trust and inclusion, accountability, honesty, and risk taking (Anfuso, 1994; Foster-FishmanandKey, 1995). The psychological empowerment model has six dimensions: Impacts / self-determination, being meaningful, Professional growth, independence/decision-making, Competence/self-efficacy and Trust. These components all contributed to a person sense of empowerment.

- Impact / self-determination, which refer to an individual, are perceived degree of influence over outcomes in one's work and family environments. People must believe that their behaviour will influence on what happens around them. In other words, an individual must have the opportunity to exert influence in order to have an impact on outcomes at work (Spreitzer, 1995). The term Choice for women means providing women with genuine opportunities to have not only their voice heard, but giving them real power to control and influence over work processes and results. Self-determination refers to everyone's internal need to control the environment (Conger and Kanungo, 1988). It is also defined as women's need to choose, to initiate and regulate actions or to choose the process and work behaviours at work; and should be perceived as an opportunity to make a choice.

- Being meaningful, if a work is going to be done by women managers or employees they should feel that it is a valuable work. They evaluate the job based on their own values and feel that they are doing something meaningful.

- Professional growth refers to personal development in job and profession. Empowered women feel more professional growth in their career as employee or managers.

- Independence/decision-making, Empowerment is related to independence. Empowered women are expected to be independent and make decision on their own. The argument of the empowerment supporters is that women should be empowered to make more decisions about their own lives.

- Competence and self efficacy points at one's work role efficacy or personal mastery; women must feel that they are competent to engage in the behaviours required by the organization or family. Empowerment is about self-actualization and competence. Competence and self-efficacy refer to enable the women to be confidence in their 


\section{Empowerment of Women: A Conceptual Framework}

capacity to make the choices. The useful exercise of every other kind of power depends on competence. Competence is acquired through formal training or education (Forrester, 2000). Self-efficacy construct is an aspect of empowerment that combines intention and belief in one's ability into a personal outcome expectation (Bandura, 1982; Mischel, 1973). It reflects the extent to which women have been both personally engaged by the organization and mobilized sufficiently to project expectations for themselves into the future.

- Trust, Empowerment is connected with trust. Trust creates an atmosphere for empowerment and grows in such an atmosphere. Trust requires values like solidarity and maturity. Empowerment cannot be installed like software but must be grown. We can't empower women, but we can create an environment in which they can empower themselves (Willis,1999: 73).

These factors can be viewed as the essential prerequisites to motivate empowering behaviours in women's life or work. Since organizations play an important role in developing women's awareness of and trust, lots of women take advantage from them. By solving problems, gaining experience, and working together, women will become aware of their own subordinate position in society and become more capable of changing it (Himmelstrand, 1990:112; Scheyvens, 2003, 27). Women need to be empowered with skills, knowledge, and confidence to determine the development path they wish to follow and to challenge the entrenched organizational structures which hamper them.

\section{RECOMMENDATIONS}

- Educate women about their human rights, personal strengths, skills, and resources to foster their vitality and resilience as personal protective factors that offset poverty.

- Engage women and girls as active partners in planning and operating programs at all decision-making levels.

- Encourage development of ownership, optimism, and confidence in their ability to be effective by providing opportunities for participating in entrepreneurial, social and other development activities.

- Encourage and provide opportunities for expanding and strengthening capacity building community networks through which information and entrepreneurial skills are shared.

- Provide and strengthen existing primary, secondary, and higher education and training of women and girls.

- Train local women peer coaches as mental health resources for the community using available technology such as online communication and instruction. Psychologists, social workers and other mental health professionals can serve the community by training peer coaches to recognize mental health problems and provide services or referrals.

- Develop and evaluate a program that deploys trained psychologists working with peer coaches to provide services and training. 
- Offer low cost insurance or government grants to provide health and mental health services in rural areas.

- Train health/mental healthcare providers to deliver accessible, informed, and nondiscriminatory services and education, addressing the unique health/mental health needs of girls and women with disabilities

\section{REFERENCES:}

1. Agarwal, B. (2001). "Gender Inequality, Cooperation, and Environmental Sustainability." In Economic Inequality, Collective Action, and Environmental Sustainability., ed. P. Bardhan, S. Bowles and J.M. Baland. Princeton University Press.

2. Anderson, S., and J.-M. Baland. (2002). "The Economics of Roscas and Intrahousehold Resource Allocation." The Quarterly Journal of Economics, 117(3), 963-995.

3. Anderson, S., and M. Eswaran. (2009). "What Determines Female Autonomy? Evidence from Bangladesh." Journal of Development Economics, 90(2), 179 - 191.

4. Anfuso, D. (1994). Kodak employees bring a department into the black. Personnel Journal, 73(9), 104-112.

5. Baird, S. (1994). Self-empowerment: Your first step toward excellence. Journal for Quality \& Participation, 17(7), 40-44.

6. Bandura, A. (1982). Self-efficacy mechanisms in human agency. American Psychologist, 37, 122-147.

7. Batliwala, S. (1994). The Meaning of Women's Empowerment: New Concept from Action. In G. Sen, A. Germain, \& L. Chen (Eds.), Population Policies Reconsidered: Health Empowerment and Rights (pp. 127-138). Cambridge: Harvard University Press.

8. Baxter, J. (1993). Work at Home: The Domestic Division of Labour. St. Lucia: University of Queensland Press.

9. Baxter, J. and M. Western (1998). "Satisfaction with housework: examining the paradox", Sociology, 32(1), 101-120.

10. Becker, G. (1973a). "A Theory of Marriage: Part I." The Journal of Political Economy, 81(4), 813- 846.

11. Becker, G. (1973b). "A Theory of Marriage: Part II." The Journal of Political Economy, 82(2), S11- S26.

12. Benin, M.H. and J. Agostinelli (1988). "Husbands' and Wives' Satisfaction with the Division of Labour", Journal of Marriage and the Family, 50, 349-61.

13. Berk, S. (1985). The Gender Factor: The Apportionment of Work in American Households. New York: Plenum Press.

14. Berman, E. M. (1995). Empowering employees in state agencies: A survey of recent progress. International Journal of Public Administration, 18(5), 833-850.

15. Blair, S. and M. Johnson (1992). "Wife's perception of the fairness of the division of household labor: The intersection of housework and ideology", Journal of Marriage and the Family, 54, 570-581.

16. Bogg, J. (1995). The practice of empowerment-Making the most of human competence. Leadership and Organization Development Journal, 16(6), 46- 47. 
17. Burbidge, J. (1995). Three tales of participation at work in government. Journal for Quality and Participation, 18(2), 20-23.

18. Caldwell, J., P. Reddy, and P. Caldwell. (1983). "The Causes of Marriage Change in South India.” Population Studies, 37(3), 343-361.

19. Cheryl E Czuba Nanette Page (1999). Empowerment: What is it?. Journal of Extension, 37, 5-14.

20. Conger, J. and Kanungo, R. (1988). "The Empowerment Process: Integrating Theory and Practice,” Academy of Management Review, v.13, no.3, pp. 471-482, 1988.

21. Connell, R. (1987). Gender and Power, Cambridge: Polity Press.

22. DeMaris, A. and M.A. Longmore (1996). "Ideology, Power, and Equity: Testing Competing Explanations for the Perception of Fairness in Household Labor", Social Forces, 74, 43-71.

23. Fawcett, S. B., White, G. W., Balcazar, F. E., Suarez-Balcazar, Y., Mathews, R. M., Paine-Andrews, A., Seekins, T., and Smith, J. F. (1994). A contextual-behavioral model of empowerment: Case studies involving people with physical disabilities. American Journal of Community Psychology, 22, 471-496.

24. Forrester, G. (2000) Professional autonomy versus managerial control: The experience of teachers in an English primary school. International Studies in Sociology of Education, 10(2), 133-151.

25. Foster-Fishman, P. G., \& Keys, C. B. (1995). The inserted pyramid: How a well meaning attempt to initiate employee empowerment ran afoul of the culture of a public bureaucracy. Academy of Management Journal Best Paper Proceeding, 364-368.

26. Fulford, M. D., \& Enz, C. A. (1995). The impact of empowerment on service employees. Journal of Managerial Issues, 7(2), 161-175.

27. Greenstein, I.N. (1996). "Gender Ideology and Perceptions of the Fairness of the Division of Household Labor: Effects on Marital Quality", Social Forces, 74, 102942.

28. Hashemi, S., S. Schuler, and A. Riley. (1996). "Rural Credit Programs and Women's Empowerment in Bangladesh." World Development, 24(4), 635 - 653.

29. Himmelstrand, K. (1990). Can an Aid Bureaucracy Empower Women? In K. Staudt (ed.) Women, International Development and Politics: the Bureaucratic Mire, pp. 101-13. Philadelphia: Temple University Press.

30. Hofstede, G. (2001). Culture's consequences: comparing values, behaviors, institutions and organizations across nations. Sage, Thousand Oaks, CA.

31. Imai, K., and P. Eklund. (2008). "Women's Organizations and Social Capital to Reduce Prevalence of Child Malnutrition in Papua New Guinea." Oxford Development Studies, 36(2), 209-233.

32. Janssens, W. (2010). "Women's Empowerment and the Creation of Social Capital in Indian Villages." World Development, 38(7), 974-988.

33. Kandpal, E., and K. Baylis. (2011). "Standing Together: Peer Networks, Female Empowerment, and Child Welfare." Working Paper. 
34. Kandpal, E., and K. Baylis. (2013). "Expanding Horizons: Can Women's Support Groups Diversify Peer Networks in Rural India?" American Journal of Agricultural Economics, 95(2), 360-367.

35. Kantor, P. (2003). "Women's Empowerment Through Home-based Work: Evidence from India." Development and Change, 34(3), 425-445.

36. Lashley, C. (1995). Towards an understanding of employee empowerment in hospitality services. International Journal of Contemporary Hospitality Management, 7(1), 27-32.

37. Lennon, M.C. and S. Rosenfield (1994). "Relative Fairness and the Division of Housework: The Importance of Options", American Journal of Sociology, 100, 506-31.

38. Malhotra, A., R. Pande, and C. Grown. (2003). "Impacts of Investments in Female Education on Gender Equality." International Center for Research on Women.

39. Mason, O., H. Smith, A. Stach and S. Philip Morgan (2002). 'Muslim Women in Southeast Asia: Do they have less autonomy than their non-Muslim sisters?, unpublished report. Washington, DC: World Bank.

40. Mischel, W. (1973). Toward a cognitive social learning reconceptualization of personality. Psychological Review, 80, 252-283.

41. Mishra, A. K. and Spreitzer, G.M. (1998). Explaining how survivors respond to downsizing: the roles of trust, empowerment, justice and work redesign, Academy of Management Review, 23(3), 567-88.

42. Neelakantan, U., and M. Tertilt. 2008. "A note on marriage market clearing." Economics Letters, 101(2), $103-105$.

43. Nelson, D. and R. Burke (2000). "Women executives: Health, stress, and success", The Academy of Management Executive, 14(2), 107-121.

44. Nixon, B. (1994). Facilitating empowerment in organizations. Leadership \& Organization Development Journal, 15(4), 3-11.

45. Osborne, S. P. (1994). The language of empowerment. International Journal of Public Sector Management, 7(3), 56-62.

46. Pleck, J. (1985). Working Wives/Working Husbands. Beverly Hills, Calif.: Sage.

47. Quisumbing, A., and B. de la Bri`ere. (2000). "Women's Assets And Intrahousehold Allocation In Rural Bangladesh: Testing Measures Of Bargaining Power." International Food Policy Research Institute (IFPRI) FCND Discussion Paper 86.

48. Rahman, L., and V. Rao. (2004). "The Determinants of Gender Equity in India: Examining Dyson and Moore's Thesis with New Data." Population and Development Review, 30(2), 239-268.

49. Russel B. (1962). Power: A New Social Analysis, London: Unwin Books.

50. Scheyvens, S. (2003). Church Women's Groups and the Empowerment of Women in Solomon Islands.

51. Schuler, S., and S. Hashemi. (1994). "Credit Programs, Women's Empowerment, and Contraceptive use in Rural Bangladesh." Studies in Family Planning, 25(2): 65-76. 
52. Sharma, K. (1991-1992). “Grassroots Organisations and Women's Empowerment: Some Issues in the Contemporary Debate", Samya Shakri: A Journal of Women's Studies, 6, 26-44.

53. Sharpe, S. (1984). Double Identity: The Lives of Working Mothers. London: Penguin.

54. Siegall M.and Gardner, S. (1999). Contetual factors of psychological empowerment, Pesonnel Review, 29(6), 703-22.

55. Spreitzer, G. M. (1995). Psychological empowerment in the workplace. Dimensions, measurement, and validation. Academy of Management Journal, 38(5), 1442-1465.

56. Stromquist. N. (1997). Literacy for Citizenship. Gender and Grassroots Dynamics in Brazil. State University of NewYork Press, Albany.

57. Sullivan, O. (1996). "Time Co-Ordination and Domestic Division of Labour and Affective Relations: Time Use and the Enjoyment of Activities within Couples", Sociology, 30, 79-100.

58. Warde A. and K. Hetherington (1993). "A Changing Domestic Division of Labour? Issues of Measurement and Interpretation", Work, Employment and Society 7, 23-45.

59. Willis, A. K. (1999). Breaking through Barriers to Successful Empowerment. Hospital Material Management, 20(4), 69-80.

60. Wolf, D. (1992). Factory daughters: Gender, household dynamics, and rural industrialization in Java. Berkeley: University. 